\title{
Hydrothermal treatment of Ti surface to enhance the formation of low crystalline hydroxyl carbonate apatite
}

\author{
Soyoung Yang, Sujeong Lee, Indu Bajpai and Sukyoung Kim
}

\begin{abstract}
Background: $\mathrm{Ti}$ and its alloys have been widely used as orthopedic and dental implants due to their outstanding mechanical properties and biocompatibility. However, long time is required to form bond between Ti implant and surrounding tissues. Therefore, these implants necessitate surface treatment such as mechanical/chemical treatment and coating of bioactive materials for improving the osseointegration.

Results: This study was focused on the calcium-phosphate (Ca-P) coating on machined Ti, blasted-Ti (B-Ti), and blasted-NaOH-etched-Ti (BNH) surfaces by hydrothermal method to evaluate the ability of HA formation. Nanostructured morphology was created by $\mathrm{NaOH}$ etching on blasted-Ti surface. XRD analysis confirmed the existence of sodium titanate phase on such samples. Rutile and anatase phases along with hydroxyapatite were observed after hydrothermal treatment in $\mathrm{Ca}-\mathrm{P}$ solution. Substantial hydroxyapatite together with $\mathrm{TiO}_{2}$ was observed during hydrothermal treatment at $200^{\circ} \mathrm{C}$ for $12 \mathrm{hrs}$. Blasted- $\mathrm{NaOH}$-etched samples (BNH-Ti) revealed appreciable bone-like apatite formation as compared to machined-Ti and blasted-Ti (B-Ti) surfaces. However, maximum HA formation was confirmed on Ca-P coated-BNH samples (BNHA-Ti-200-12) by XRD and ICP analysis.
\end{abstract}

Conclusion: Multistep surface treatment adopted in current study would be effective to enhance HA formation on Ti surface.

Keywords: Titanium, Hydrothermal treatment, $\mathrm{NaOH}$-etching, SBF test, Ca-P coating

\section{Background}

Although, durability of Titanium (Ti) implants has been already proven in biomedical field, slow as well as poor implant-bone interface are still a big challenge. To resolve this issue, various surface modifications using physical, chemical methods and coating with bioactive material were used to promote early osseointegration and fixation $[1,2]$. Surface modification by physical treatment such as girt-blasting and machining improved the biomechanical fixation between implant and human body [3]. Bioactive surfaces were achieved by chemical treatment with acid/ alkali solution. Especially, Sodium titanate subjected to soaking in SBF solution and subsequent heat-treatment formed bone like apatite-layer [4]. In addition, some researcher groups have studied about coating method

\footnotetext{
* Correspondence: sykim@ynu.ac.kr

Materials Science and Engineering, Yeungnam University, 280 Daehak-Ro, Gyeongsan, Gyeongbuk 712-749, South Korea
}

such as plasma spraying, sol-gel, electron beam sputtering with bioactive materials. Plasma spray coating has been widely utilized with hydroxyapatite (HA) and bioglass. Although, owing advantage in terms of obtaining high crystallinity on surface, it was found to be difficult to control the thickness and week adhesion at the coatingsubstrate interface [5]. Sol-gel and dip-coating with HA, bioglass and water glass were reported to be easy method of coating on implant surface [6]. Park et. al reported that coating using water-glass sol was effective for apatite layer formation and cell activation. However these kinds of physical coating methods exhibited week adhesion strength on metal surface [7].

On the other hands, hydrothermal method seemed to be relatively simple and effective due to chemical reaction as well as coating. Although to be stable materials at an ambient temperature, the chemical reaction of those could be promoted under the condition of hydrothermal treatment. Hamade et al. conducted surface coating with 
hydrothermal treatment using $\mathrm{CaO}$ solution. They reported that hydrothermal treatment in $\mathrm{CaO}$ solution enhanced the precipitation of apatite on the titanium surface [8]. Ishikawa et al. proposed that $\mathrm{Ti}-\mathrm{O}-\mathrm{Ca}$ boding formed by hydrothermal treatment in $\mathrm{CaCl}_{2}$ solution was effective for the fabrication of titanium implant with good bioactivity and osteoconductivity $[9,10]$. Hu et al. referred to a onestep hydrothermal process with hydroxyapatite (HA) suspension to coat Ti surface [11].

In this study, multiple surface treatment processes such as grit-blasting, $\mathrm{NaOH}$ etching and hydrothermal treatment on the Ti surfaces were conducted to improve the bone-like apatite formation and early osseonintegration. Especially, this study was focused on the calcium phosphate coating by hydrothermal method on various types of surface such as $\mathrm{Ti}$, blasted $\mathrm{Ti}$ (B-Ti), and blasted- $\mathrm{NaOH}$ etched $\mathrm{Ti}$ (BNH-Ti) and evaluation of apatite forming ability on these surfaces in SBF environment. The appropriate treatment conditions for the bioactive coating were investigated in terms of temperature and time of hydrothermal treatment. Calcium phosphate coating was conducted by hydrothermal treatment at $120,160,200^{\circ} \mathrm{C}$ for $3,6,12,24$ hrs. Surface chemistry and morphology of calcium phosphate coated $\mathrm{Ti}$ surface were characterized using SEM and XRD. The ability of forming bone-like apatite layer was studied in SBF.

\section{Methods}

\section{Preparation of the samples}

Firstly, commercially pure Ti discs (cp-Ti, grade 4) with $12 \mathrm{~mm}$ diameter and $2 \mathrm{~mm}$ thickness were polished using $\mathrm{SiC}$ papers (Daesung, Korea). Then polished discs were blasted using 250-300 HA grits and then washed with 1 vol\% $\mathrm{HCl}$ solution in an ultrasonic bath for 2 mins to remove HA residues on the surfaces. These discs were again cleaned in an ultrasonic bath with pure water and ethanol to remove the $\mathrm{HCl}$ residues from the $\mathrm{Ti}$ discs. Lastly, washed Ti discs were soaked into a $5 \mathrm{~N} \mathrm{NaOH}$ solution at $60^{\circ} \mathrm{C}$ for $24 \mathrm{hrs}$, followed by subsequent heat treatment at $600^{\circ} \mathrm{C}$ for $1 \mathrm{~h}$.

\section{Hydrothermal treatment}

Calcium phosphate $(\mathrm{Ca}-\mathrm{P})$ solution was prepared by mixing $20 \mathrm{mM}$ of calcium nitrate tetrahydrate and $12 \mathrm{mM}$ of disodium phosphate for $12 \mathrm{~h}$ on magnetic stirrer and $\mathrm{pH}$ was adjusted to 11 by titrating with $\mathrm{NH}_{4} \mathrm{OH}$. Ti, B-Ti, BNH-Ti were fixed into the teflon jig and prepared calcium phosphate solution was filled in a teflon vessel. The vessel was heated at 120,160 and $200^{\circ} \mathrm{C}$ for $3,6,12$ and $24 \mathrm{~h}$. Furthermore, calcium phosphate coated $\mathrm{Ti}$ substrates was rinsed with pure water for several times and dried in oven at $60^{\circ} \mathrm{C}$.

\section{Biomineralization}

Surface treated Ti discs were soaked in a $40 \mathrm{ml}$ of simulated body fluid (SBF) solution at $36.5^{\circ} \mathrm{C}, 80 \mathrm{rpm}$ in a shaking incubator for 1,7 days. SBF was prepared by dissolving $\mathrm{NaCl}, \mathrm{NaHCO}_{3}, \mathrm{KCl}, \mathrm{K}_{2} \mathrm{HPO}_{4} \cdot 3 \mathrm{H}_{2} \mathrm{O}, \mathrm{MgCl}_{2}$. $6 \mathrm{H}_{2} \mathrm{O}, \mathrm{CaCl}_{2}, \mathrm{Na}_{2} \mathrm{SO}_{4}$ and Tirs- (hydorxymethyl) aminomethane in ultra-pure water and titrated at $\mathrm{pH} 7.40$ using $1 \mathrm{M} \mathrm{HCl}$, which was nearly equal to ion concentrations $\left(\mathrm{Na}^{+} 142.0 \mathrm{mM} / \mathrm{L}, \mathrm{K}^{+} 5.0 \mathrm{mM} / \mathrm{L}, \mathrm{Mg}^{2+} 1.5 \mathrm{mM} /\right.$ $\mathrm{L}, \mathrm{Ca}^{2+} 2.5 \mathrm{mM} / \mathrm{L}, \mathrm{Cl}^{-} 103.0 \mathrm{mM} / \mathrm{L}, \mathrm{HCO}_{3}^{-} 4.2 \mathrm{mM} / \mathrm{L}$, $\mathrm{HPO}_{4}{ }^{2-} 1.0 \mathrm{mM} / \mathrm{L}, \mathrm{SO}_{4}{ }^{2-} 0.5 \mathrm{mM} / \mathrm{L}$ ) in human blood plasma was used to estimate bioactivity [12].

\section{Characterization of the Ti surface}

The modified-Ti surfaces were analyzed using thin-film X-ray diffraction (PANalytical, Netherlands) to identify the phases. The surface morphology and chemical composition of samples were observed under FE-SEM (field emission scanning electron microscopy, Hitachi, Japan) and EDS (energy dispersive X-ray spectroscopy, Hitachi, Japan). The weight changes of the specimens were examined before and after immersion in SBF solution by an electronic balance (4-digit accuracy balance, AND HR120, Japan). Concentration of calcium and phosphorus ions remained in solution after SBF test was measured by ICP-AES (OPTIMA8300, Perkin Elmer, USA).

\section{Results and discussion}

Surface microstructure of machined titanium (Ti), blasted $\mathrm{Ti}$ with HA grits (B-Ti), chemically etched $\mathrm{Ti}$ with a sodium hydroxide solution $(\mathrm{N}-\mathrm{Ti})$ and blasted- $\mathrm{NaOH}$ etched $\mathrm{Ti}$ (BNH-Ti) were shown in Figure 1. Macro sized coarse surface (Figure $1 \mathrm{~b}$ ) was verified after blasting with HA whereas nano-sized porous network structure was confirmed after soaking in sodium hydroxide solution at $60^{\circ} \mathrm{C}$ for 1 day (Figure 1c). Surface topography of blasted $-\mathrm{NaOH}$ etched-Ti surface (Figure 1d) was observed to be composed of nano-sized network structure on the coarse surface.

Hydrothermally treated surfaces of $\mathrm{BNH}-\mathrm{Ti}$ substrates (named as BNHA-Ti) at $120,160,200^{\circ} \mathrm{C}$ for $3,6,12$, $24 \mathrm{hrs}$ were shown in Figure 2. The rod-type of HA crystals appeared on the surface after hydrothermal treatment. The rod-type of anatase crystals as well as HA crystals were observed at higher temperature and in longer reaction time. Anatase crystals came out on the surface of titanium from inside after hydrothermal treatment at $200^{\circ} \mathrm{C}$ for $6 \mathrm{hrs}$. Therefore, mixed-structure was formed as $\mathrm{HA}$ and anatase after hydrothermal treatment at $200^{\circ} \mathrm{C}$ for $12 \mathrm{hrs}$. However, the anatase crystals predominated rather than HA by further heat-treatment. On the basis of such observations, $\mathrm{Ti}$ and $\mathrm{B}-\mathrm{Ti}$ samples were hydrothermally treated at 120 and $200^{\circ} \mathrm{C}$ for $12 \mathrm{hrs}$ 


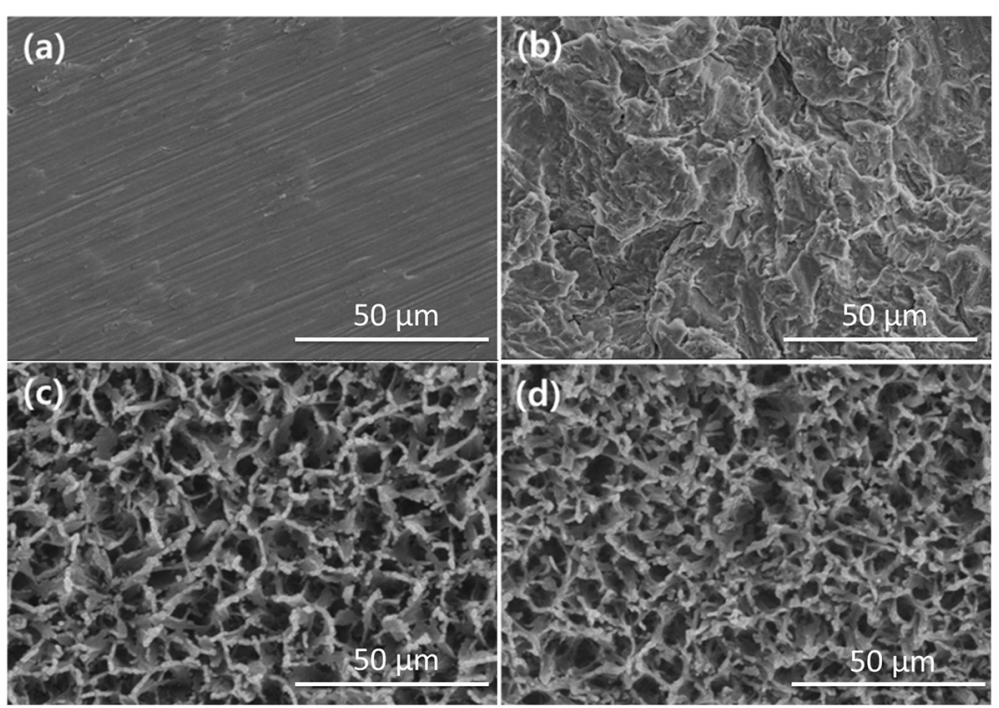

Figure 1 Surface morphology of (a) Machined- (Ti), (b) blasted- (B-Ti), (c) NaOH etched- (N-Ti) and (d) blasted-NaOH etched Ti (BNH-Ti).

in $\mathrm{Ca}-\mathrm{P}$ solution (Figure 3) and anatas- $\mathrm{TiO}_{2}$ and $\mathrm{HA}$ crystals were observed at $200^{\circ} \mathrm{C}$ treatment temperature.

Various type of titanium surfaces were immersed into simulated body fluid (SBF) for 1 to 7 days to observe apatite formation activity. The surface micrographs of $\mathrm{Ti}$, B-Ti, BNH-Ti, BNHA-Ti after soaking in SBF solution at $37^{\circ} \mathrm{C}$ were shown in Figure 4. Apatite layers did not appear on $\mathrm{Ti}$ and B-Ti surface after soaking in SBF solution for 1 and 7 days. Apatite nucleation was observed on $\mathrm{BNH}-\mathrm{Ti}$ and BNHA-Ti surfaces after 1 day immersion in $\mathrm{SBF}$, but it was significantly increased on BNHA-Ti surface after 7 days.

Figure 5 showed the ICP analysis of remained calcium and phosphorus ions concentration in SBF solution with immersion time of specimens. The concentration of calcium and phosphorus was not changed on mechanically

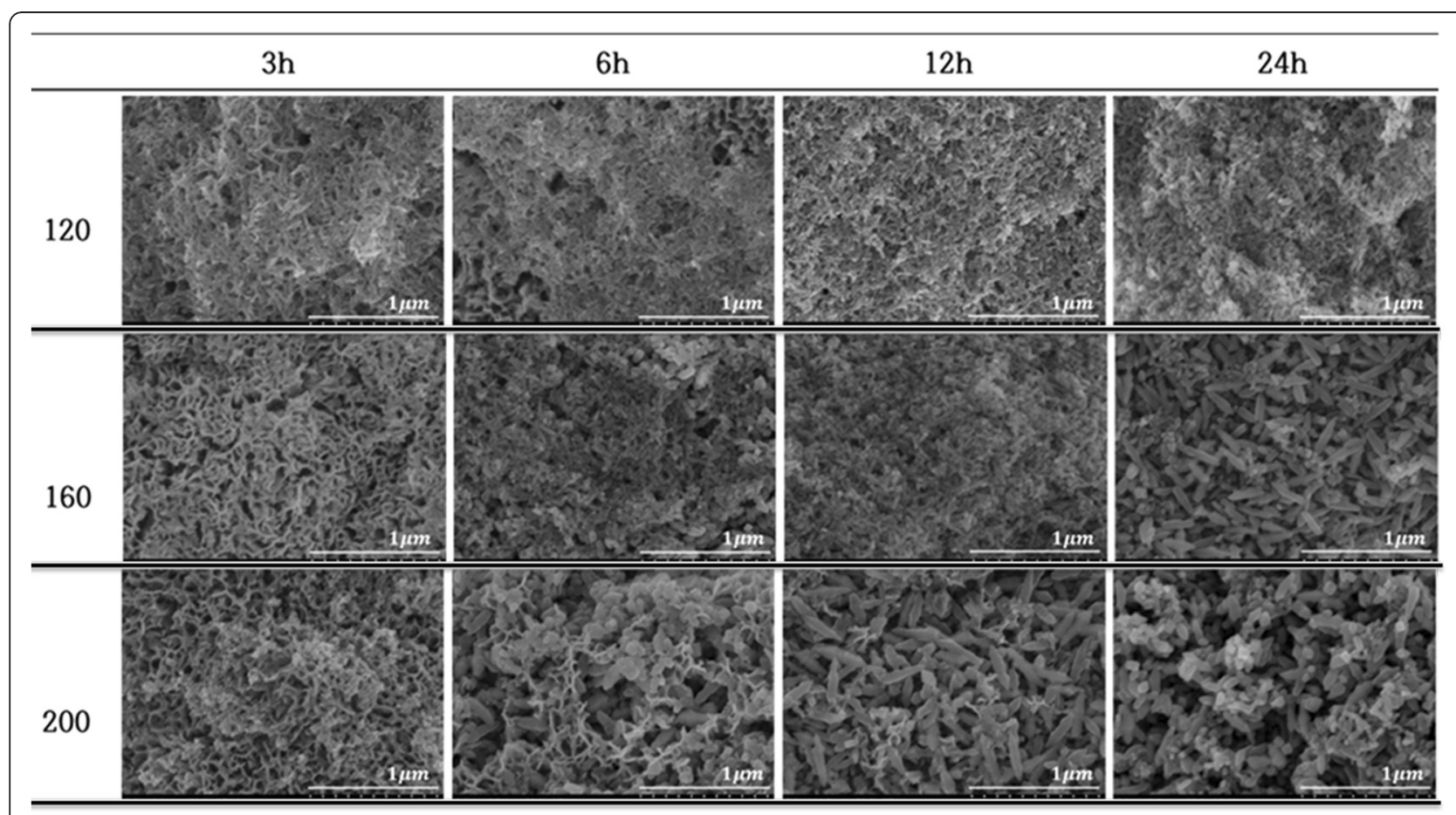

Figure 2 SEM images of hydrothermally treated blasted-NaOH etched-Ti samples (BNHA-Ti) in calcium phosphate solution with pH10 at 120,160 and $200^{\circ} \mathrm{C}$ for $3,6,12$ and $24 \mathrm{hrs}$. 


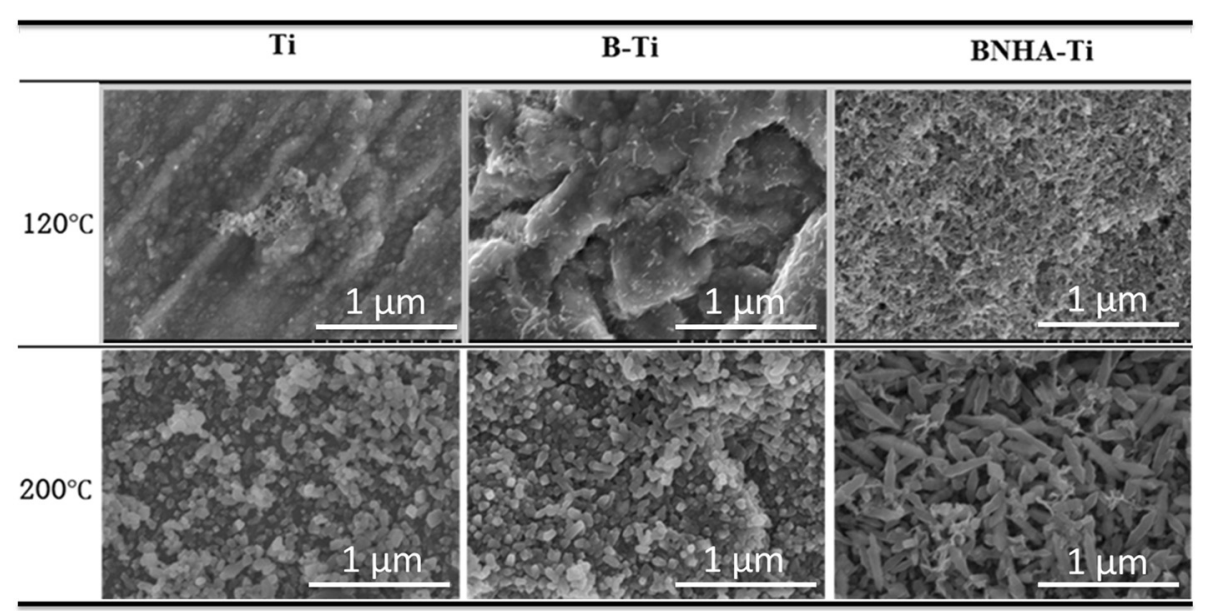

Figure 3 SEM images of Ti, B-Ti, BNHA-Ti by hydrothermal treatment in calcium phosphate solution with pH 10 at 120 and $200^{\circ} \mathrm{C}$ for 12 hrs.

treated $\mathrm{Ti}, \mathrm{B}-\mathrm{Ti}$ surfaces during immersion upto 7 days. On the other hand, in case of hydrothermally treated BNHA-Ti specimen, concentration of calcium and phosphorus was decreased with immersion time. Also, the concentrations of calcium and phosphorus which remained in SBF after removing hydrothermally treated specimens (Ti-200-12, B-Ti-200-12) were rapidly decreased. It was considered that the decrease of calcium and phosphorus concentrations in SBF was due to the precipitation of apatite on the titanium surface. Therefore it was expected to be effective for the formation of apatite on the hydrothermally treated surface than chemically treated. It was believed that hydrothermally treated surfaces were effective for nucleation of apatite than the others.

XRD analysis of $\mathrm{Ti}, \mathrm{BNH}-\mathrm{Ti}, \mathrm{BNHA}-\mathrm{Ti}-200-12$ and BNHA-Ti-200-12 after SBF test for 1, and 7 days were shown in Figure 6. Sodium titanate appeared on the

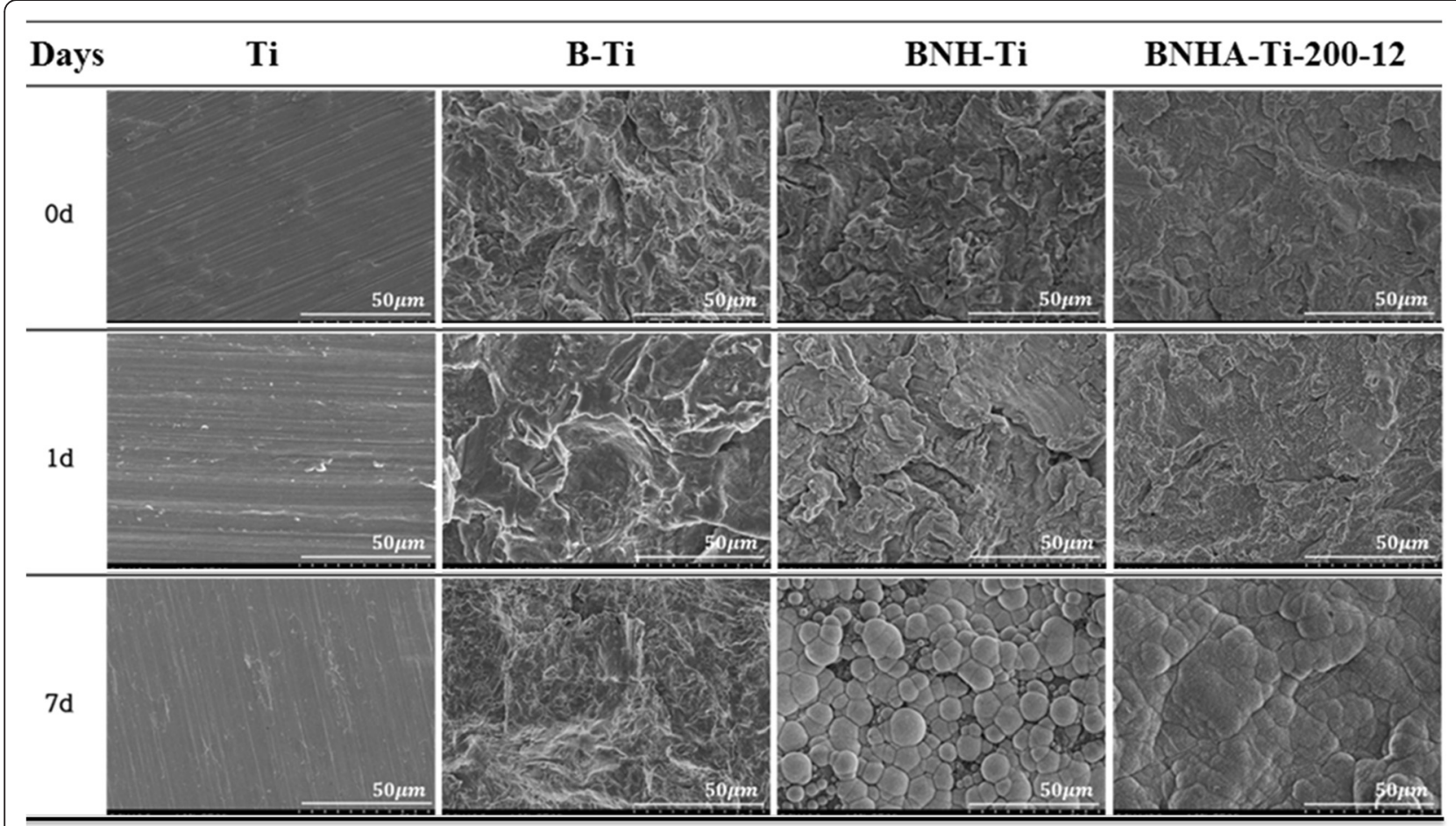

Figure 4 SEM images of surfaces of Ti, B-Ti, BNH-Ti, BNHA-Ti-200-12 after soaking in SBF solution at $37^{\circ} \mathrm{C}$ for 0,1 and 7 days. 

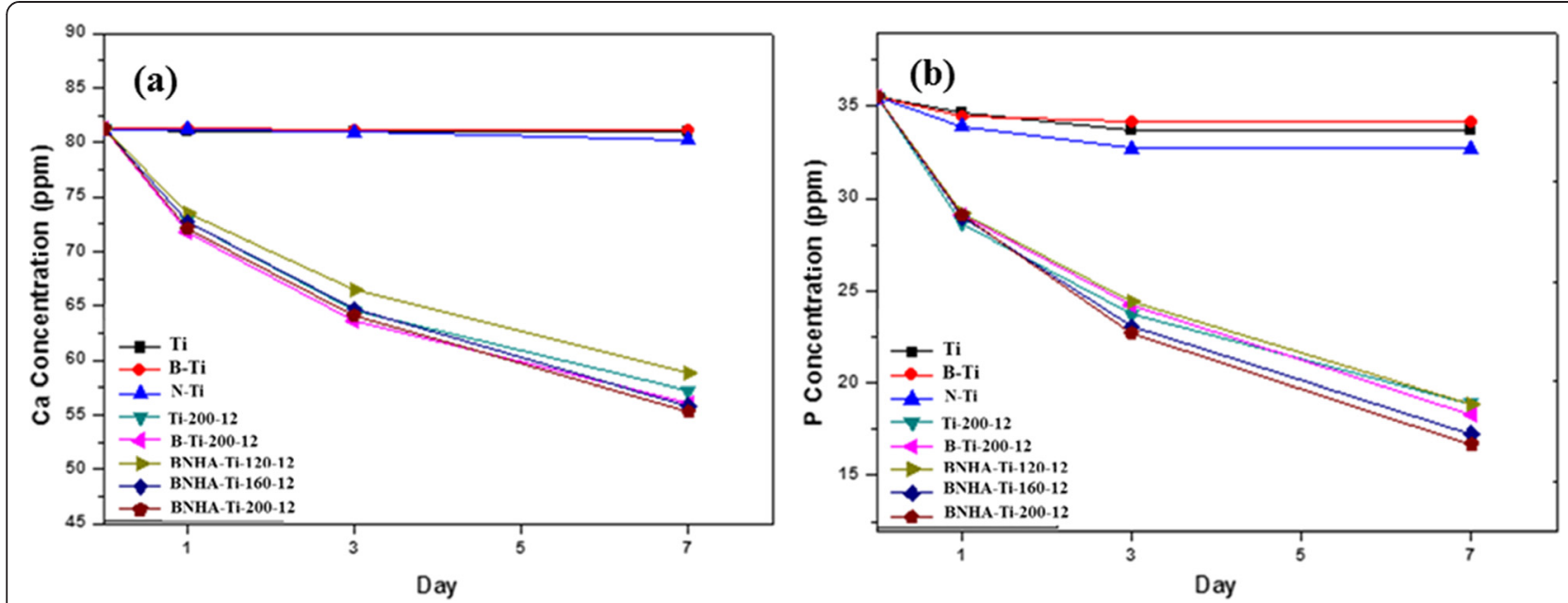

Figure 5 Concentrations of remained $\mathrm{Ca}$ and $\mathrm{P}$ ions in SBF after 1, 3 and 7 day immersion of various types of titanium samples; machined, and blasted, alkali etched, blasted-etched.

chemically treated surface with $\mathrm{NaOH}$ solution (BNH-Ti). It confirmed HA phase after coating with calcium phosphate suspension by hydrothermal method. Although, one day immersion of BNHA-Ti-200-12 samples in SBF slightly increased HA precipitation on the surface, significant increase in intensity corresponding to HA was observed after 7 days. It was found that calcium phosphate layer coated after several heat treatments was highly effective for the formation of the apatite in simulated body fluid.

As it was evident from the results that $\mathrm{NaOH}$ etched Ti surface (BNH-Ti) showed significantly better apatite formation ability than the machined-Ti and blasted-Ti surfaces. The reason behind this is that sodium and oxygen ions entered into the Ti surface during the reaction, which led to formation of sodium titanate and titanium dioxide [4]; both phases were clearly identified by XRD analysis of BNH sample (Figure 6). When these etched samples were exposed in SBF solution, sodium ions were exchanged with $\mathrm{H}_{3} \mathrm{O}^{+}$in $\mathrm{SBF}$ and formed $\mathrm{Ti}-\mathrm{OH}$ bond whereas released sodium ions increased local $\mathrm{pH}$ of the sample surface that activated the apatite precipitation [4]. When $\mathrm{NaOH}$-etched-Ti samples were hydrothermally treated in Ca-P solution, sodium ions were released in the

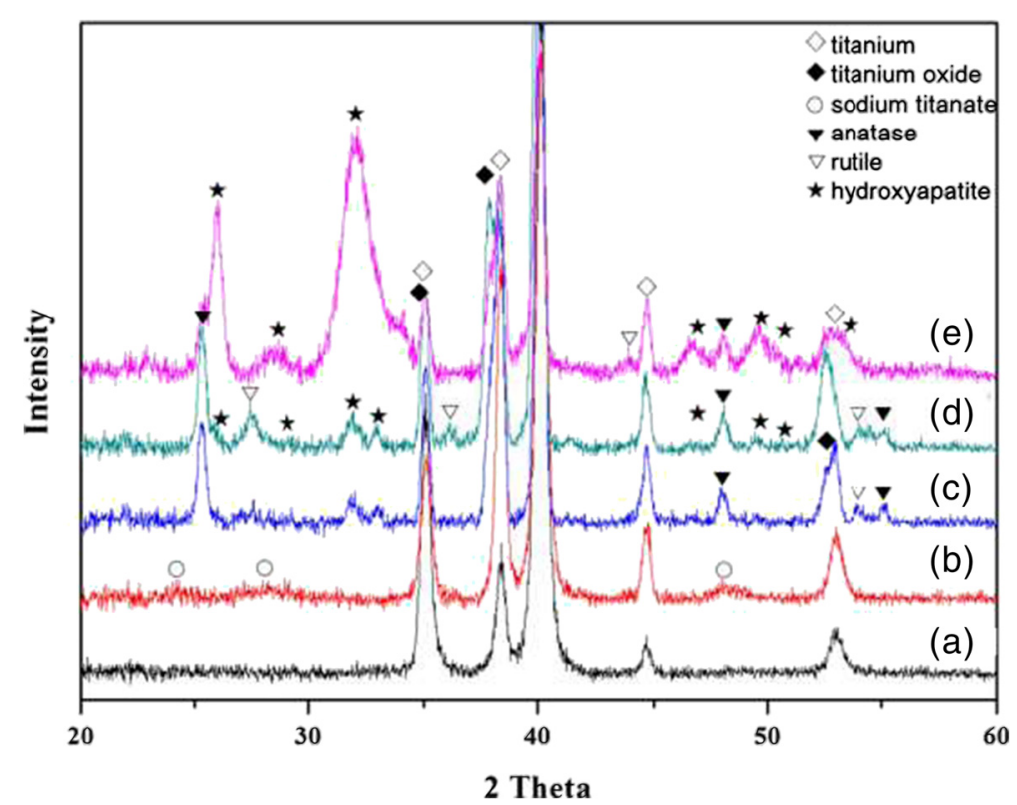

Figure 6 XRD patterns of (a) machined-Ti, (b) BNH-Ti, (c) BNHA-Ti-200-12, (d) BNHA-Ti-200-12 immersed in SBF solution for 1 day, and (e) BNHA-Ti-200-12 immersed in SBF solution for 7 days. 
reaction solution and positively charged $\mathrm{Ca}^{+2}$ ions accumulated in the groves of the surface and reacted with negatively charged $\mathrm{PO}_{4}^{-3}$ ions of the solution to form a stable phase as crystalline hydroxyapatite. XRD analysis (Figure 6) and microstructure (Figure 2) of BNH200-12 samples showed the existence of $\mathrm{TiO}_{2}$ rods and hydroxyapatite. Subsequently, when BNHA-Ti-200-12 samples were exposed to SBF solution, inherently present hydroxyapatite on the surface worked as nucleation sites and stimulated the bone-like apatite formation on the surface. As indicated by the ICP analysis of the SBF solution, all samples hydrothermally treated in Ca-P solution showed better apatite precipitation than the machined $\mathrm{Ti}$ and blasted Ti. In addition, among all Ti surfaces, maximum as well as fastest bone-like apatite precipitation was observed on multistep treated Ti samples (BNHA-Ti200-12) as indicated by highest intensity corresponding to HA peak in Figure 6 as well as ICP analysis (Figure 5), where the maximum loss of calcium and phosphorous ions from SBF solution indicated the highest carbonate HA formation.

\section{Conclusions}

In the current work, multiple ways of surface treatments as blasting, alkali etching and Ca-P coating were carried out to improve bioactivity of $\mathrm{Ti}$ surface. Particularly, sodium titanate was observed on blasted-Ti surface after etching in $\mathrm{NaOH}$ solution. Hydroxyapatite crystals were formed easily on titanium surface during hydrothermal treatment. Moreover, HA layer on the surface was enhanced with increasing temperature and time. Though, manifest HA layer along with analase was formed on all of samples (Ti, B-Ti, BNH-Ti) after hydrothermal treatment at high temperature $\left(200^{\circ} \mathrm{C}\right)$ for $12 \mathrm{hrs}$. However, anatase was found to be dominant than HA as further hydrothermal treatment (for $24 \mathrm{hrs}$ ) inhibited formation of HA on the surface. For this reason, the proper temperature and time were important to form HA during hydrothermal treatment. It was confirmed that the hydrothermally treated surface was effective to form bone-like apatite layer in SBF test. Maximum carbonate HA on Ti surface was found at the multistep treated $\mathrm{Ti}$ surface (BNHA-Ti-200-12). In conclusion, hydrothermal method with calcium phosphate suspension was found to be simple and effective method for HA coating on Ti implants.

\section{Availability of supporting data}

The data sets supporting the results of this article are included within the article.

\section{Competing interests}

The authors declare that they have no competing interests.

\section{Authors' contributions}

SY and SL carried out experiments. IB helped in writing the manuscript. SK supervised the work and he is the corresponding author as well. All authors read and approved the final manuscript.

\section{Acknowledgements}

This research was supported by Basic Science Research Program through the National Research Foundation of Korea(NRF) funded by the Ministry of Education, Science and Technology (NRF-2012R1A1A4A01014136).

Received: 18 November 2014 Accepted: 28 November 2014 Published online: 20 January 2015

\section{References}

1. Van Noort R. The implant material of today. J Mater Sci. 1987;22:3801-11.

2. Lee K, Park S, Lim H, Koh J, Kang S, Kim H, et al. A recent research and development tendency of dental titanium implant. Jaeryomadang. 2009;22 (4):33-40.

3. Jonéhennec $L$, Soueidan A, Layrolle P, Amouriq Y. Surface treatments of titanium dental implants for rapid osseointegration. Dent Mater. 2007:23:844-54.

4. Kokubo T, Yamadama S. Novel bioactive titanium layers formed on Ti metal and its alloys by chemical treatment: review. Materials. 2010;3:48-63.

5. Tsui YC, Doyle C, Clyne TW. Plasma sprayed hydroxyapatite coatings on titanium substrates part 1: mechanical properties and residual stress levels. Biomaterials. 1998;19(22):2015-29.

6. Seema K, Uma B, Suchita K. Transformations in Sol-gel synthesized nanoscale hydroxyapatite calcined under different temperatures and time conditions. JMEPEG. 2012;21:1737-43.

7. Solip P, Sujeong L, In-Hwan S, Sukyoung K. Water glass coating on a T substrate to form $\mathrm{Si}-\mathrm{OH}$ groups for improving cell behaviors of dental implants, Korean. J Met Mater. 2014;52(2):173-80.

8. Hamada K, Kon M, Hanawa T, Yokoyama K, Miyamoto Y, Asaoka K. Hydrothermal modification of titanium surface in calcium solutions. Biomaterials. 2002;23:2265-72

9. Nakagawa M, Zhang L, Udoh K, Matruya S, Ishikawa K. Effects of hydrothermal treatment with $\mathrm{CaCl} 2$ solution on surface property and cell response of titanium implants. J Mat Sci Mat In Med. 2005;16:985-91.

10. Valanezahad A, Ishikawa K, Tsuru K, Maruta M, Matsuya S. Hydrothermal calcium modification of $316 \mathrm{~L}$ stainless steel and its apatite forming ability in simulated body fluid. Dent Mater J. 2011;30:749-53.

11. Hu X, Shen H, Cheng Y, Xiong X, Wang S, Fang J, et al. One-step modification of nano-hydroxyapatite coating on titanium surface by hydrothermal method. Surface \& Coating Technol. 2010;205:2000-6.

12. Oyane A, Kim H, Furuya T, Kokubo T, Miyazaki T, Nakamura T. Preparation and assessment of revised simulated body fluids. J Biomed Materials Res. 2003;65:188-95.

\section{Submit your next manuscript to BioMed Central and take full advantage of:}

- Convenient online submission

- Thorough peer review

- No space constraints or color figure charges

- Immediate publication on acceptance

- Inclusion in PubMed, CAS, Scopus and Google Scholar

- Research which is freely available for redistribution 